\title{
Bronchiolitis in children
}

\section{Umasankar $N^{I}$}

${ }^{1}$ Department of Paediatrics, Faculty of Medicine, Jaffna

\section{Abstract}

Bronchiolitis is the commonest lower respiratory tract infection in infants needing hospital admission. It is caused by the virus mainly the respiratory syncytial virus. The infants typically present with initial upper respiratory symptoms such as rhinitis, nasal congestion and low grade fever which is followed by tachypnea recessions grunting apnoea and cyanosis in severe cases. Young age group, prematurity congenital heart diseases are the major risk factors for the severe disease. Diagnosis of bronchiolitis is mainly depended on clinical features. Clinical assessment of a child suspected with bronchiolitis should include clinical features to diagnoses the bronchiolitis and to assess the severity of the bronchiolitis. There is no definitive management for bronchiolitis. None of the drugs tried in the management of bronhiolitis have shown their efficacy in reducing the length of hospital stay, severity of the illness or improvement in the outcome. The main stay of management is supportive like minimum handling, supplementary oxygen, and care on fluid and nutrition and ventilator support whenever needed.

\section{Introduction}

Lower respiratory tract infections are the common cause for hospital admission in children. They accounts for $20-30 \%$ of inpatient hospital admission of children less than 5 year old. (1, 2) The leading cause of death among younger children is also the lower respiratory infection. (2) Acute bronchiolitis is the commonest lower respiratory tract infection in infants and it represents the important causes of hospitalization in this age group.Hospital admission dueto bronchiolitis consumes significant burden on healthcare cost as the management needs oxygen and sometimes ventilator support in the intensive care unit.

\section{Clinical definition of Bronchiolitis}

There is no clear definition for bronchiolitis accepted worldwide. In June 2013, American Academy of Paediatrics revised the 2016 bronchiolitis guidelines and defined the bronchiolitis as a "constellation of clinical signs and symptoms occurring in children younger than 2 years, including a viral upper respiratory tract prodrome followed by increased respiratory effort and wheezing".

\section{Epidemiology and Global burden}

Nearly $20 \%$ of infants need hospital visits due to bronchiolitis. (4) The prevalence of bronchiolitis is progressively increasing in the recent past. Annual rates of hospital visit due to bronchiolitis is increased by $41 \%$ over the 5 years period from 1997 to 2003 and annual hospitalization due to bronchiolitis is also increased by nine fold over a period of 32 years from 1979 to 2011.(4,5)

The estimated PICU admission rate ranged between 1.3 to1.6 per 1000 infants aged < 1 year with most vulnerable age group is $0-2$ months. (5) Among the children younger than one year who admitted with bronchiolitis $1 \%$ needed endotracheal intubation and ventilation support.

The mortality due to bronchiolitis is 2.2 per 
100,000 live birthsand it remains stable over the 19 years from 1979 to 1997.(6)

\section{Pathophysiology}

Respiratory Syncytial Virus (RSV) is the commonest cause for bronchiolitis. It accounts for 60 to $80 \%$ of children with bronchiolitis. $(7,8,9)$ Other viruses which are responsible for bronchiolitis are Rhinovirus, Human Metapneumo Virus, Adenovirus Human boca virus, influenza virus and Para influenza virus $(8,9)$. More than one viruses were detected in nearly $30 \%$ of the children with bronchiolitis (10).

The infection starts in the upper respiratory tract and spread to lower respiratory tract within a few days. Acute bronchiolitis is characterized by bronchiolar obstruction with oedema, mucus and cellular debris.

Both direct invasion of the organism and immune mediated response of the respiratory cells causes damage in bronchiolitis, Necrosis of the respiratory epithelium, excessive mucus production, and peribronchiolar lymphocytic infiltration result in sub mucosal oedema. Cytokines and chemokine released by the infected respiratory epithelial cells amply the immune response by increasing cellular infiltration. Interferon- $\gamma$, interleukin 4 , interleukin 8 and interleukin 9 are found in high concentration in respiratory secretions of infants with bronchiolitis. Epithelial necrosis, oedema and mucus secretion causes airflow obstruction distal air trapping and atelectasis. IgE-mediated reactions and release of inflammatory mediators result in exacerbation of acute obstruction and may contribute to chronic obstructive pulmonary dysfunction, a common sequela of bronchiolitis. $(11,12)$

\section{Risk factors for bronchiolitis.}

There are few risk factors identified for RSV bronchiolitis. They are young age, male sex, born prematurely, preexisting disease such as bronchopulmonary dysplasia, chronic lung disease, congenital heart disease, neuromuscular diseases, no/short duration of breast feeding, exposure to environmental tobacco smoke, young maternal age and high parity. But most infants who are hospitalized due to RSV bronchiolitis are born at term and have no identified risk factors. (13) The chronological age is the single most important predictor of severity of the disease. Nearly two thirds of hospitalization due to RSV bronchiolitis occurs within the age of 5months and the highest percentage is between1-3months. $(7,13)$

\section{Clinical features}

The clinical features of bronchiolitis typically begin with features of upper respiratory tract infection such as low grade fever, rhinitis with or without nasal congestion and irritating cough. After 1-3 days this will progress to tachypnoea, wheezing and increased respiratory effort manifested as grunting, nasal flaring, and intercostal and/or subcostal or supraclavicular retractions.(3)

The clinical examination will reveal tachypnoea, recession, use of accessory muscles and nasal flaring. Grunting, apnoea and cyanosis are seen in infants affected with severe bronchiolitis. On auscultation of chest reveals fine inspiratory crackles in young infants and high pitched expiratory wheeze and prolonged expiration in older children.

\section{Assessment}

\section{Clinical assessment}

Bronchiolitis is a clinical diagnosis. The assessment should include to diagnose the bronchiolitis and to assess the severity of the illness. Assessment of severity begins with adequate history to identify the risk factors such as prematurity underlying cardiac disease, lung disease or neuromuscular disease and period of breastfeeding.

Several tools have studied to assess the severity of bronchiolitis, but none have shown their effectiveness in predicting the severity. (14) The severity of bronchiolitis is classified into three groups as mild, moderate and severe based 
on Australasian Bronchiolitis Guideline. (15) (Table 1)

Table 1: Classification of bronchiolitis

\begin{tabular}{|c|c|c|c|}
\hline & Mild & Moderate & Severe \\
\hline Behaviour & Normal & $\begin{array}{l}\text { Some/in- } \\
\text { termittent } \\
\text { irritability }\end{array}$ & $\begin{array}{l}\text { Increasing } \\
\text { irritability } \\
\text { and/or leth- } \\
\text { argy Fatigue }\end{array}$ \\
\hline $\begin{array}{l}\text { Respiratory } \\
\text { Rate }\end{array}$ & $\begin{array}{l}\text { Normal } \\
\text { to mild } \\
\text { tachy- } \\
\text { pnoea }\end{array}$ & $\begin{array}{l}\text { Increased } \\
\text { respiratory } \\
\text { rate }\end{array}$ & $\begin{array}{l}\text { Marked } \\
\text { increase or } \\
\text { decrease in } \\
\text { respiratory } \\
\text { rate }\end{array}$ \\
\hline $\begin{array}{l}\text { Use of } \\
\text { muscles }\end{array}$ & $\begin{array}{l}\text { Nil to } \\
\text { mild } \\
\text { chest wall } \\
\text { retraction }\end{array}$ & $\begin{array}{l}\text { Moderate } \\
\text { chest wall } \\
\text { retractions } \\
\text { Tracheal } \\
\text { tug } \\
\text { Nasal } \\
\text { flaring }\end{array}$ & $\begin{array}{l}\text { Marked } \\
\text { chest wall } \\
\text { retractions } \\
\text { Marked tra- } \\
\text { cheal tug } \\
\text { Marked na- } \\
\text { sal flaring }\end{array}$ \\
\hline $\begin{array}{l}\text { Oxygen sat- } \\
\text { uration / } \\
\text { oxygen re- } \\
\text { quirement }\end{array}$ & $\begin{array}{l}\text { O2 sat- } \\
\text { urations } \\
\text { greater } \\
\text { than 92\% } \\
\text { (in room } \\
\text { air) }\end{array}$ & $\begin{array}{l}\text { O2 satu- } \\
\text { rations } 90 \\
-92 \% \\
\text { (in room } \\
\text { air) }\end{array}$ & $\begin{array}{l}\text { O2 satura- } \\
\text { tions less } \\
\text { than } 90 \% \\
\text { (in room air) } \\
\text { Hypoxemia, } \\
\text { may not } \\
\text { be corrected } \\
\text { by } 02\end{array}$ \\
\hline $\begin{array}{l}\text { Apnoeic } \\
\text { episodes }\end{array}$ & None & $\begin{array}{l}\text { May have } \\
\text { brief ap- } \\
\text { noea }\end{array}$ & $\begin{array}{l}\text { May have } \\
\text { increasingly } \\
\text { frequent or } \\
\text { prolonged } \\
\text { apnoea }\end{array}$ \\
\hline Feeding & Normal & $\begin{array}{l}\text { May have } \\
\text { difficulty } \\
\text { with } \\
\text { feeding or } \\
\text { reduced } \\
\text { feeding }\end{array}$ & $\begin{array}{l}\text { Reluctant } \\
\text { or unable to } \\
\text { feed }\end{array}$ \\
\hline
\end{tabular}

\section{Laboratory assessment}

Bronchiolitis is a clinical diagnosis. Laboratory or $-18-$ radiographic studies are not routinely needed to diagnose and manage bronchiolitis. $(3,16)$ Routine radiographic studies (CXR) is not recommended as it does not improve the management of bronchiolitis and it is considered when another diagnosis is suspected or if there is no improvement at the expected rate. Routine virology testing has no role in the management. (16)

\section{Management}

\section{General management}

The management of bronchiolitis is mainly supportive and there is no definitive management for bronchiolitis. None of the drugs showed tried in the management of bronhiolitis have shown their efficacy in reducing the length of hospital stay, severity of the illness or improvement in the outcome.

Minimal handling is beneficial. Nasal suctioning is not recommended as a routine practice, and it may be beneficial in children with respiratory distress or feeding difficulties because of upper airway secretions. (16)

\section{Oxygen}

Oxygen should be administered for children with hypoxia due to bronchiolitis. It can be given via face mask or nasal cannulae if the oxygen saturation is less than $92 \%$.

\section{Fluid and nutrition}

Bronchiolitis causes significant respiratory distress which may limit the feeding in infants. Maintaining the hydration is vital in the management of bronchiolitis. Mild to moderate bronchiolitis may be managed with small frequent breast feeding but infants with severe bronchiolitis may warrant either nasogastric feeds or Intra venous fluids for the maintenance of hydration.

\section{Inhaled saline}

Inhaled normal $(0.9 \%)$ saline is commonly used in the management of bronchiolitis to clear the secretions. But none of the management guidelines on bronchiolitis routinely recommends its usage. Only a few evidence suggest that the 
$3 \%$ saline is safe and effective at improving symptoms of mild to moderate bronchiolitis after its usage for 24 hours, and reduced the length of hospital stay when the hospital stay is more than 3 days. But there is no evidence to support its use in emergency department where the use is short duration and there is no reduction in hospital admission due to use of $3 \%$ saline. (3)

\section{Inhaled bronchodilator}

The national guideline on the management of bronchiolitis not recommends using inhaled beta 2 agonists in infants with bronchiolitis. Results of the Cochrane review indicates that there is no benefit in using inhaled bronchodilators in the clinical course of infants with bronchiolitis. The potential adverse effects (tachycardia and tremors) of these agents outweigh any potential benefits.

The studies have proven that the use of nebulized epinephrine did not significantly reduce the length of the hospital stay in infants admitted to the hospital with bronchiolitis. $(15,17,18)$

\section{Systemic steroids}

There is no proven benefit in the use of local or systemic steroids in the management of bronchiolitis thus the routine use of steroids in the management of bronchiolitis is not recommended. $(3,15)$

\section{Antibiotics and anti-viral agents}

Routine use of antibiotic is not recommended in children with bronchiolitis. The studies have shown that the use of antibiotic does not reduce the length of hospital stay or improvement in clinical course. However antibiotics may be considered when there is concomitant bacterial infection. $(3,15)$

There is no place for routine antiviral treatment in the management of bronchiolitis. The studies have shown that the Ribavirin (antiviral) use does not significantly affect the mortality or shorten the hospital stay in routine use and need further evaluation to prove its beneficial effect. $(19,20)$ Vol.31, No.1, July 2019

\section{Noninvasive and invasive ventilator support in bronchiolitis}

Continuous positive airway pressure (CPAP) with nasal cannula or facemask is used in children with severe bronchiolitis and hypoxia. The studies have shown that the CPAP reduced the work of breathing in children with bronchiolitis but there is no clear evidence to support the improvement in the outcome of children who treated with CPAP. (21)

Heated humidified high floor nasal cannula (HHHFNC) oxygen is the relatively new mode of noninvasive ventilator support to deliver the oxygen to children with bronchiolitis and hypoxia. It is relatively safe to use in the wards and it improve the work of breathing in children with severe bronchiolitis. The studies have shown the early use of HHHFNC reduced the need for invasive ventilation and need for ICU care treatment. (22) Now the HHHFNC is used as the first line of noninvasive ventilator mode in children with bronchiolitis in many countries.

Even though noninvasive ventilator support reduces the need for invasive ventilator support in children with bronchioltis the last resort for those infants not improving with noninvasive ventilation is the invasive ventilaror support in the ICU.

There are several interventions used in critically ill infants with bronchiolitis such as surfactant, ribavirin, immune globulin, systemic corticosteroids, vitamin A, interferon, erythropoietin, and heliox. But currently there are no clear effective interventions available to improve the outcome of critically ill infants with bronchiolitis. (23)

In summary bronchiolitis is the commonest cause of lower respiratory tract infection in infants. As its high prevalence in this age group and the severity of illness needing ICU care contributes to the burden of bronchiolitis on healthcare cost. Respiratory syncytial virus is the commonest aetiolgical agent but there can be more than one viruses. Several identified risk factors contribute for the severity of the illness but there is no tools shown their efficacy in predicting the severity.

Diagnosis is clinical and the clinical should focus on identifying the risk factor and the severity of 
the illness. Management is mainly supportive to correct the hypoxia and feeding. Even though several drugs have been tried in the management of bronchiolitis a few drugs showed their efficacy in the improvement of work of breathing but none of the drugs have shown the efficacy in the improvement of the outcome of bronchiolitis.

\section{References}

1. EdmundAS Nelson John STam LMYuAlbert M Li Paul KS Chan Rita YT Sung; Assessing disease burden of respiratory disorders in Hong Kong children with hospital discharge data and linked laboratory data; Hong Kong Med J 2007;13:114-21

2. Theo Vos ; Global and national burden of diseases and injuries among children and adolescents between 1990 and 2013: findings from the Global Burden of Disease 2013 Stud; JAMA Pediatr. 2016;170(3):267287. doi:10.1001

3. Shawn L. Ralston, Allan S. Lieberthal, H. Cody Meissner, Brian K. Alverson, Jill E. Baley, Anne M. Gadomski, David W. Johnson, Michael J. Light, Nizar F. Maraqa, Eneida A. Mendonca, Kieran J. Phelan, Joseph J. Zorc, DanetteStankoLopp, Mark A. Brown, Ian Nathanson, Elizabeth Rosenblum, Stephen Sayles III, Sinsi Hernandez-Cancio; Clinical Practice Guideline: The Diagnosis, Management, and Prevention of Bronchiolitis. PEDIATRICS2014, 134(5) doi: 10.1542

4. Kecia N. Carroll, TebebGebretsadik, Marie R. Griffin, Pingsheng Wu, William D. Dupont, Edward F. Mitchel, Rachel Enriquez, Tina V. Hartert; Increasing Burden and Risk Factors for Bronchiolitis-Related Medical Visits in Infants Enrolled in a State Health Care Insurance Plan; PEDIATRICS 2008,122 58-64. doi: 10.1542

5. Green CA, Yeates D, Goldacre A, et al. Admission to hospital for bronchiolitis in England; trends over five decades, geographical variation and association with perinatal characteristics and subsequent asthma. Arch Dis Child; 2016; 101: 140-
146. doi:10.1136

6. David K. Shay Robert C. Holman, Genie E. Roosevelt Matthew J. Clarke, Larry J. Anderson; Bronchiolitis-Associated Mortality and Estimates of Respiratory Syncytial Virus-Associated Deaths among US Children, 1979-1997; The Journal of Infectious Diseases 2001;183:16-22

7. Ghazaly, M. \&Nadel,S; Characteristics of children admitted to intensive care with acute bronchiolitis; European Journal of Pediatrics 2018; 177: 913. https://doi. org/10.1007/s00431-018-3138-6

8. C CalvoFPozo ML GarcíaGarcía M Sanchez M Lopez Valero P Pérez Breña I Casas; Detection of new respiratory viruses in hospitalized infants with bronchiolitis: a three year prospective study; ACTA PAEDIATRICA 2010; 99 (6) $883-887 ;$ https://doi.org/10.1111 lj.1651-2227.2010.01714.

9. Gokce S, Kurugol Z, Cerit Z, Cicek C. The Effect of Respiratory Syncytial Virus on the Severity of Acute Bronchiolitis in Hospitalized Infants: A Prospective Study from Turkey, Iranian Journal of Pediatric. 2018;28(2):e61034. doi: 10.5812/ijp.61034

10. H. Kim Brand Ronald de Groot Joep M.D. Galama Marianne L. Brouwer Karin Teuwen Peter W.M. Hermans Willem J.G. Melchers AdiliaWarris; Infection with multiple viruses is not associated with increased disease severity in children with bronchiolitis; Paediatric pulmonology 2012; 47(4) https://doi.org/10.1002/ppul.21552

11. Alexander K.C. Leung, James D. Kellner, H. Dele Davies, Respiratory Syncytial Virus Bronchiolitis; JOURNAL OF THE NATIONAL MEDICAL ASSOCIATION 2005; 97(12).

12. John P. DeVincenzo; A New Direction in Understanding the Pathogenesis of Respiratory Syncytial Virus Bronchiolitis: How Real Infants Suffer, The Journal of Infectious Diseases,2007; 195(8); 1084- 
1086, https://doi.org/10.1086/512622

13. Caroline Breese Hall, M.D., Geoffrey A. Weinberg, M.D., Marika K. Iwane, Ph.D., M.P.H., Aaron K. Blumkin, M.S., Kathryn M. Edwards, M.D., MaryA. Staat, M.D., M.P.H., Peggy Auinger, M.S., Marie R. Griffin, M.D., M.P.H., Katherine A. Poehling, M.D., M.P.H., Dean Erdman, Dr.P.H., Carlos G. Grijalva, M.D., M.P.H., Yuwei Zhu, M.D., M.S., et al. The Burden of Respiratory Syncytial Virus Infection in Young Children; New England Journal of Medicine 2009; 360:588-598; DOI: 10.1056/NEJMoa0804877

14. Ricardo M. Fernandes, Amy C. Plint, Caroline B. Terwee, Cristina Sampaio, Terry P. Klassen, Martin Offringa, Johanna $\mathrm{H}$. van der Lee; Validity of Bronchiolitis Outcome Measures; PEDIATRICS $2015 ; 135(6)$. Downloaded from www.aappublications. org/news by guest on March 3, 2019

15. Australasian Bronchiolitis Guideline;http:// www.predict.org.au/download/ Australasian-bronchiolitis-guideline.pdf

16. Bronchiolitis in children: diagnosis and management; NICE guideline; June 2015; https://www.nice.org.uk/guidance/ng9

17. Hartling L, Bialy LM, Vandermeer B, Tjosvold L, Johnson DW, Plint AC, Klassen TP, Patel H, Fernandes RM. Epinephrine for bronchiolitis. Cochrane Database of Systematic Reviews 2011;6. Art. No.: CD003123. DOI: 10.1002/14651858. CD003123.pub3.

18. Claire Wainwright, Luis Altamirano, Marise Cheney, et al; A Multicenter, Randomized, Double-Blind, Controlled Trial of Nebulized Epinephrine in Infants with Acute
Bronchiolitis; New England Journal of Medicine 2003; 349:27-35; DOI: 10.1056/ NEJMoa022226

19. King VJ, Viswanathan M, Bordley WC, et al. Pharmacologic Treatment of Bronchiolitis in Infants and Children: A Systematic Review. Arch PediatrAdolesc Med. 2004;158(2):127-137. doi:10.1001/ archpedi.158.2.127

20. CLINICAL PRACTICE GUIDELINE; Diagnosis and Management of Bronchiolitis; Subcommittee on Diagnosis and Management of Bronchiolitis; Endorsed by the American Academy of Family Physicians, the American College of Chest Physicians, and the American Thoracic Society. www.pediatrics.org/cgi/ doi/10.1542/peds.2006-2223; Downloaded from www.aappublications.org/news by guest on March 18, 2019.

21. OnDonlan M, Fontela PS, Puligandla PS: Use of continuous positive airway pressure (CPAP) in acute viral bronchiolitis: a systematic review. Pediatr Pulmonol. 2011, 46: 736-746. 10.1002/ppul.21483.

22. Ingvild Bruun Mikalsen, Peter Davis, and Knut Øymar; High flow nasal cannula in children: a literature review; scand J Trauma Resusc Emerg Med. 2016; 24: 93; doi: 10.1186/s13049-016-0278-4

23. Caroline Davison, Kathleen M. Ventre, Marco Luchetti, and Adrienne G. Randolph; Efficacy of interventions for bronchiolitis in critically ill infants: A systematic review and meta-analysis; PediatrCrit Care Med. 2004; 5(5): 482-489. 